\title{
The Effect of Metabolic Products of Streptomyces Avermectilis on the Dynamics of Currant Bud Mite on Blackcurrant Seedlings with a Closed-Root System in Seed-Field Conditions
}

\author{
Svetlana N. VITYAZ ${ }^{1^{*}}$ and Evgeniya A. DYUKOVA ${ }^{1}$ \\ ${ }^{1}$ Kuzbass State Agricultural Academy, Kemerovo, Russian Federation \\ *Correspondence: svetlana_vityaz@mail.ru
}

\begin{abstract}
The article presents the data from a study of the dynamics of Currant bud mite in a seed-field "Flora-Garden" LLC in Kemerovo for 2018-2019 and describes the influence of metabolic products of Streptomyces avermectilis contained in the biological preparation Fitoverm on its characteristics. Two-year-old seedlings of blackcurrant (Ribes nigrum L.) variety Ilya Muromets with a closed-root system were used as planting material. The plants were treated during the gemmation period at the end of the first May decade with the hand sprayer "ORION-6", the flow rate was 500 l/ha. The phytophage mass output was observed during the ovary formation in the third May decade in 2018 and in the second May decade in 2019. It was found that the metabolic products of Streptomyces avermectilis reduced the Currant bud mite yields during the studied period by 1.5 times, as well as influenced the phytophage population dynamics, which became uniform without peaks of mass output.
\end{abstract}

Keywords: migration dynamics, currant bud mite, blackcurrant, phytophage, closed-root system.

\section{Introduction}

A currant bud mite (Cecidophyes ribis Westw.) - is a representative of the genus Cecidophyopsis from the family Eriophyidae (Trombidiformes) of the order Trombidiformes, a narrow oligophagous parasitic on the vegetative and generative organs of blackcurrant (Ribes nigrum L.), which in turn leads to dramatic decrease in plant's productivity $[1$, p. 16] In addition, currant bud mite is a carrier of a dangerous disease - reversion or terry [2, p. 28], leading to infertility of currants [3, p. 42].

According to published data, the developmental phases of the bud mite depend on phenophase of the Ribes nigrum L. So, during the flowering period of the currant, the currant bud mites begin to migrate and populate new buds [4, p. 20]. It is known that under different climatic conditions, migration of the currant bud mites takes place at different times [5, p. 102].

In this regard, knowledge of peculiarities of the currant bud mite's life cycle allows taking high-quality protective measures at appropriate time, since the mite's population control is carried out during its migration [6, p. 60].

At present, biological preparations based on metabolic products of microorganisms are widely used to control the number of phytophages [7, pp. 104-109]. Thus, for example, 
the main active material widely used against nematodes and arthropods is Avermectins, which are obtained from the mycelial mass of Streptomyces avermitilis (strain VNIISKHM54 or strain VNIISKHM-51; Patent of the Russian Federation. The preparation "Fitoverm" is used against the complex plant pests). They enter the body of the phytophage by contact or through the digestive system. The control of the phytophage abundance is due to the neurotoxic method of exposure to metabolic products of these fungi [8, p. 64].

Due to the increasing demand for planting material of berry crops with a closed-root system, one of the main tasks today is to provide the customer with quality planting material protected from phytophages. Blackcurrant is one of the most popular berry crops among seedlings of fruit plants. Seedlings with a closed-root system are under stressful conditions, as long-term container growing negatively affects the immunity of plants. This provokes the appearance of such a dangerous phytophage as a currant bud mite (Cecidophyes ribis Westw.). Since the biology of the currant bud mite and methods for controlling the dynamics of its migration when using the metabolic products of microorganisms on plants with a closed-root system is practically not studied, therefore this topic is quite relevant.

In this regard, the aim of the research was to study the effect of metabolic products of Streptomyces avermectilis on the population dynamics of the currant bud mites on seedlings of blackcurrant with a closed-root system.

The objectives of the study included to identify the population dynamics of the currant bud mites in the seed-field "Flora-Garden" LLC in Kemerovo and to determine the degree of influence of metabolic products of Streptomyces avermectilis on the migration dynamics of this phytophage.

\section{Materials and Methods}

A study of the migration dynamics of currant bud mites on seedlings of blackcurrant with a closed-root system in the seed-field was conducted from May 9, 2018 to June 28, 2019 and from May 13, 2019 to June 28, 2019.

The research observed two-year-old seedlings of blackcurrant variety Ilyia Muromets. This is a tall bush with a columnar crown, not prone to lodging. The sprouting are long upright, height is above $1.5 \mathrm{~m}$. This variety was obtained by crossing two varieties Gooryanka and Unokar. Berry ripening starts from the third decade of July. The advantages of the variety include high winter hardiness, resistance to terry and powdery mildew. Berries have a rich black color, large fruit mass from 2 to $4 \mathrm{~g}$. This is a dessert variety.

The study of the migration dynamics of currant bud mites was carried out according to the method of S.I. Antonyuk [9, p. 26] using catching chambers (Figure 1). Pieces of plastic film served as catching chambers, which were wrapped around an infected bud and fixed on both sides of sprouting with thread. The inner surface of the chambers was covered with a thin layer of glycerol to fix the mite. The number of pest was recorded under a binocular periodically once every 3-4 days. The studies were conducted in the territory of the seed-field "Flora-Garden" LLC in Kemerovo. 


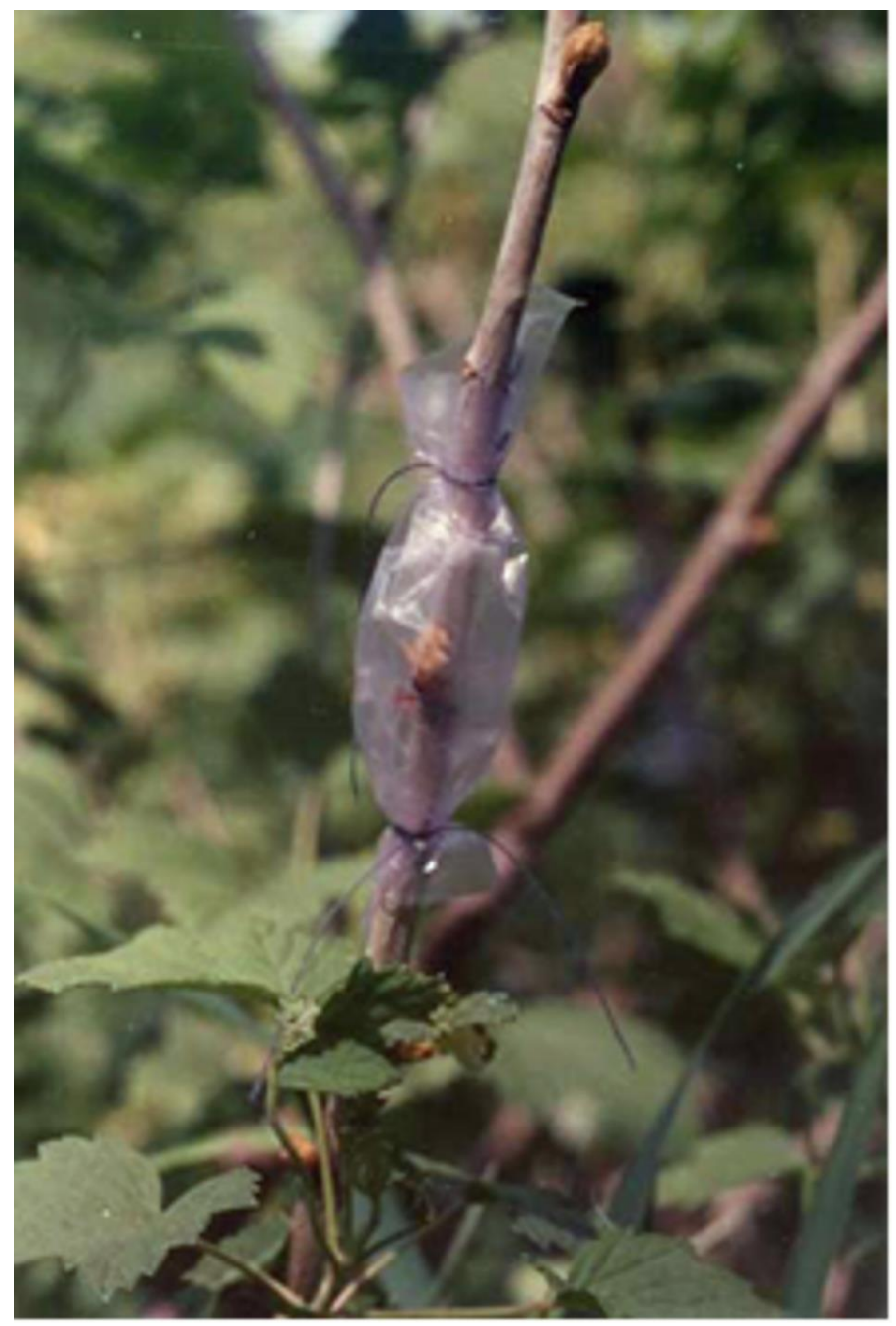

Figure 1. Catching chambers for currant bud mite

To study the effect of the metabolic products of microorganisms on the population dynamics of currant bud mites, plants were treated with a biological preparation Fitoverm in an acceptable concentration of $0.4 \%$. The composition of this preparation includes an ethanolic extract of avermectins from the actinomycete mycelial mass of Streptomyces avermitilis strain VNIISKHM-54 or strain VNIISKHM-51. The drug causes paralysis and then the death of pests.

To calculate the biological effectiveness of the preparation, the Abbot's formula was used. Statistical data processing was performed by analysis-of-variance method using the program SNEDECOR for Windows.

\section{Results and Discussion}

Migration of the bud mite from infected buds in the seed-field "Flora-Garden" LLC in Kemerovo began on May 10 (2018) and May 13 (2019), during the gemmation phase and continued regardless of the year of study until the end of June, which coincided with the beginning of berry staining (Figure 2). 


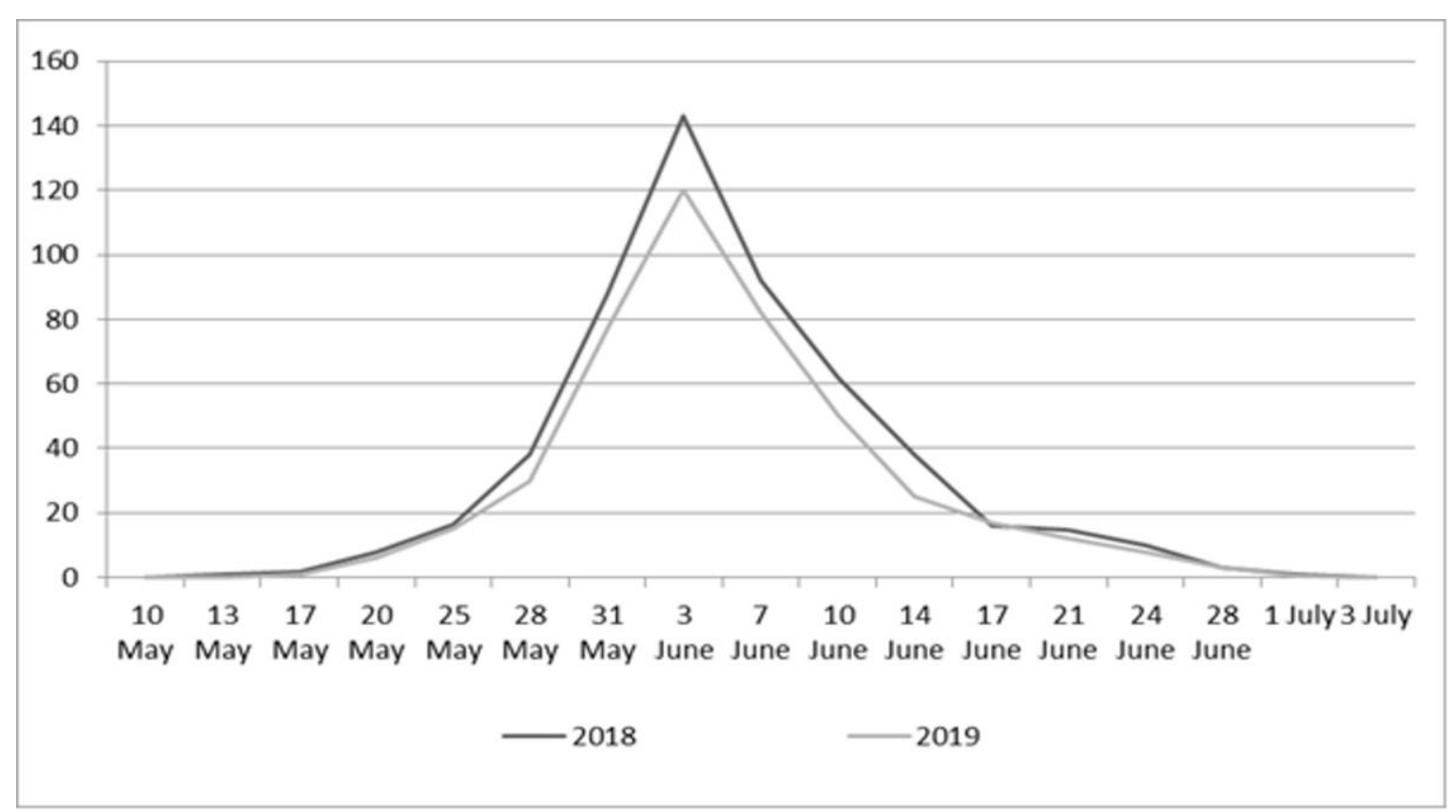

Figure 2. Dynamics of the currant bud mite coming out from the buds of blackcurrant variety Ilyia Muromets

The peak of the bud mite coming out activity was during the period from May 13 (end of flowering) to June 2 (formation and growth of the ovary) (Figure 3). From mid to late May 59\% (2018) and 60\% (2019) of bud mites migrated; in the first ten days of June, the percentage of phytophage output decreased by 34\% (2018 and 2019), in the second and third decades this indicator did not exceed $14-16 \%$ of individuals. Thus, the bulk of the pest migrated in the second half of May and reached its maximum on the eighth day from the start of the research, which coincided with the phenophase of the ovary formation.

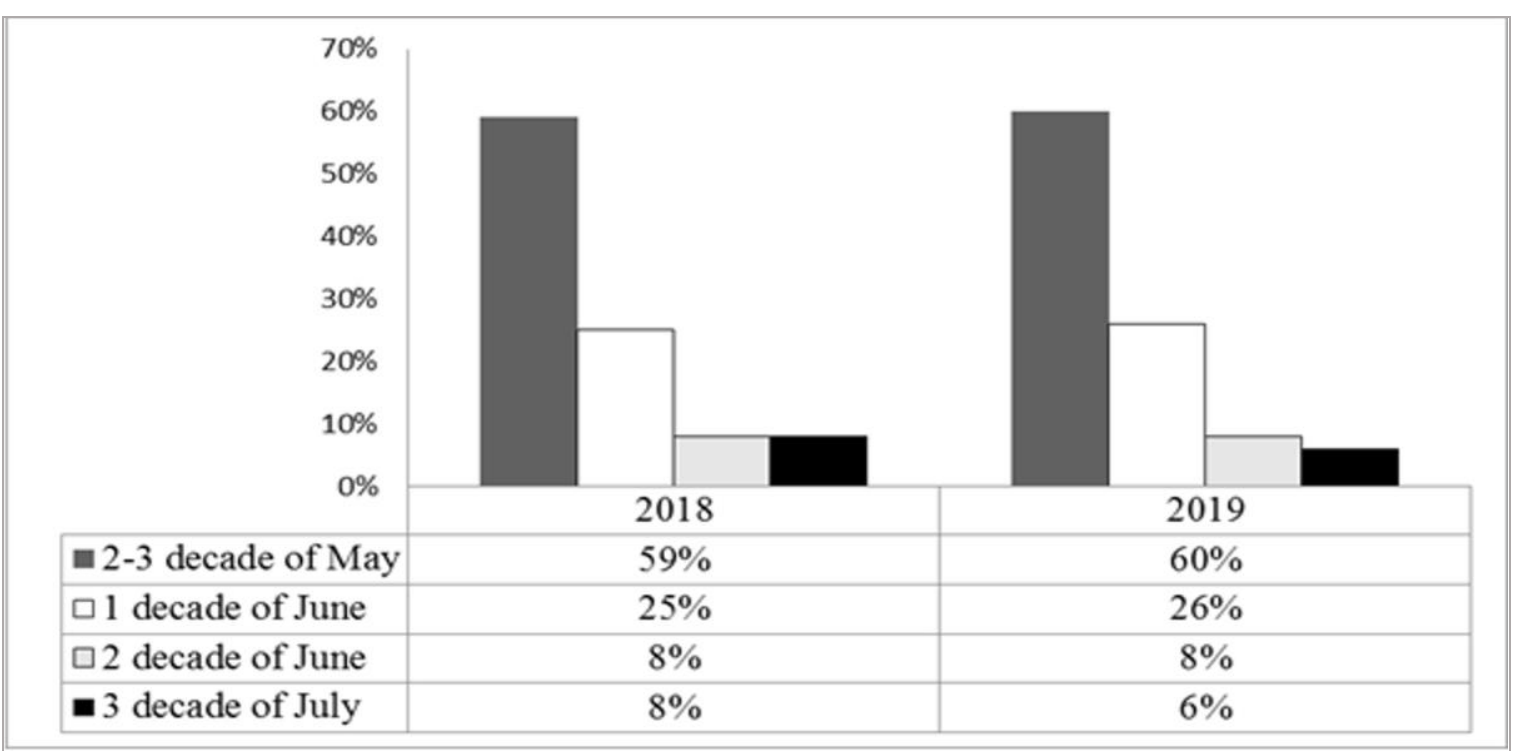

Figure 3. The dynamic rate of the currant bud mites coming out from buds of blackcurrant variety Ilya Muromet 
Migration of bud mites is associated with weather conditions, the phase of its development and the state of infected buds. The longer the last year infected buds retain freshness and do not dry out, which is facilitated by the growth processes activity, shaded shrubs and moderately humid warm weather, the longer the period of stay and reproduction of mites inside the buds [5, p. 100; 10].

In 2018 and 2019, May was warm and humid. The average monthly temperature was above the norm by $1.3^{\circ} \mathrm{C}(2018)$ and $1.4^{\circ} \mathrm{C}$ (2019). The amount of precipitation in this period was 155\% (2018) and 160\% (2019) of the norm. At the same time, in the second decade of May when mass migration of Cecidophyopsis ribis occurred, the temperature exceeded the norm by $4.4^{\circ} \mathrm{C}(2018)$ and $4.6^{\circ} \mathrm{C}$ (2019). During this period, the affected buds were in a swollen and loosened state, which facilitated the exit of the mites.

To study the effect of metabolic products of Streptomyces avermectilis on the migration dynamics of currant bud mites, during the study period, the plants were treated with the biological preparation Fitoverm in concentration of $0.4 \%$ according to the recommendations of the List of approved preparation (2018). Plants were treated during the period of bud swelling at the end of the first decade of May with the hand sprayer ORION-6, the flow rate was $500 \mathrm{l} / \mathrm{ha}$. Plants that were not treated were used as control (Figure 4). The effectiveness of the preparation was recorded every 5 days until July 1.

According to the data of 2018, a mass coming out of currant bud mite was observed from May 28 to June 03, and in 2019 from May 30 to June 5. In this regard, during this period, additional censuses of the phytophage were carried out.

Statistical analysis of experimental data showed that phytophage migration from the plants treated with a preparation containing Streptomyces avermectilis metabolic products differed from the control one regardless of the study year. Over the entire period, 379 pests (2018) and 316 (2019) were caught in catching chambers, which was almost 1.5 times less than in the control group. The migration dynamics was uniform regardless of the year of study and, in contrast to the control of the peak of mass exit of the mite, was not recorded.

\section{Conclusions}

Based on the studies, it can be argued that the dynamics of the bud mite was greatly influenced by the temperature regime and the phenological phase of plant development. The mass coming out of the phytophage was observed in the third decade of May 1 decade of June during the ovary formation. The use of metabolic products of Streptomyces avermectilis affect the control of the phytophage abundance and reduce the yield of currant bud mites by 1.5 times.

Thus, the use of metabolic products of Streptomyces avermectilis can be used to control the dynamics of migration and control the number of currant bud mites. Application of this preparation allows refusing chemical methods for plant protection of this species. This in turn helps to maintain a healthy entomofauna and produce environmentally friendly products. 


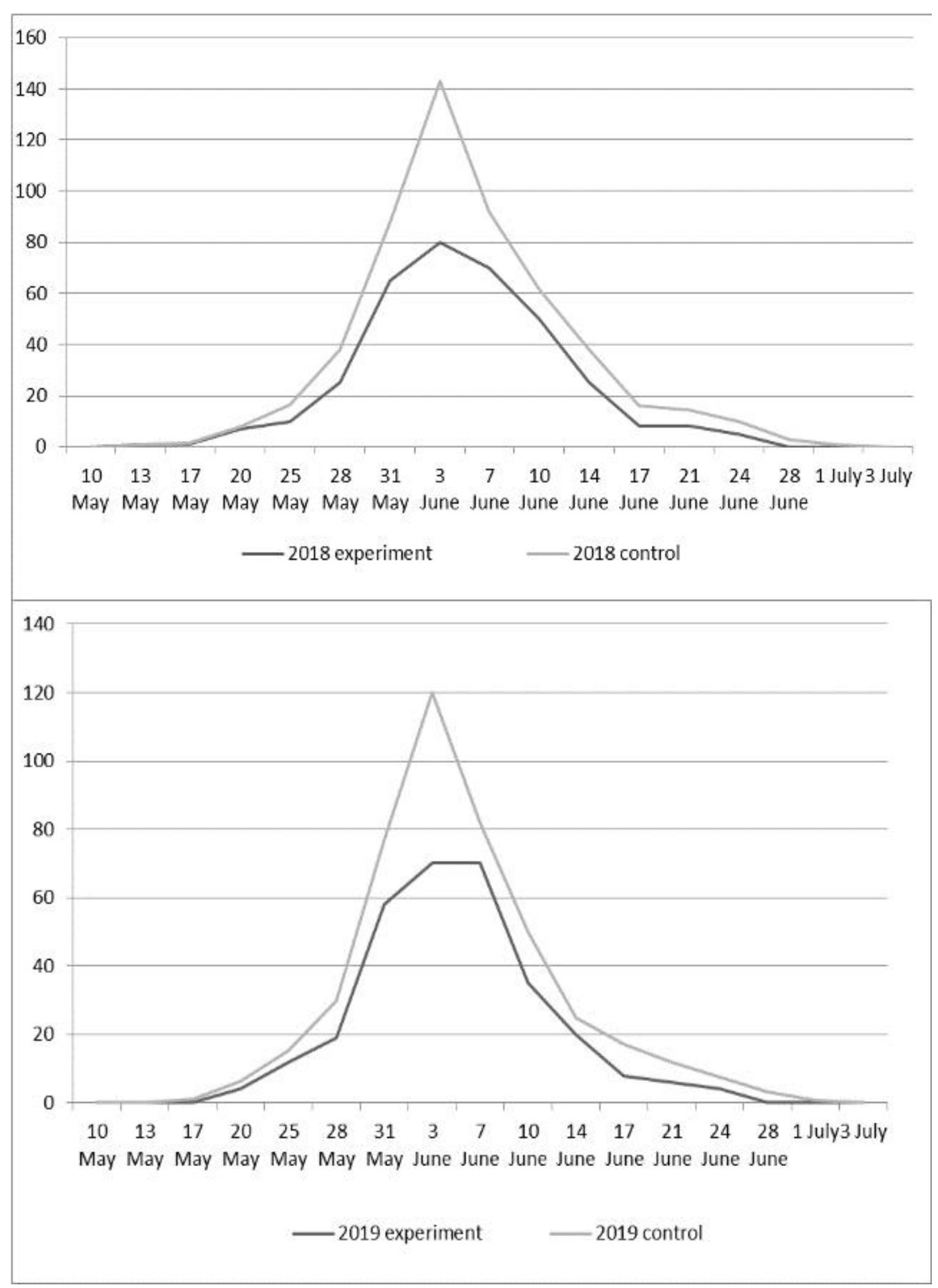

Figure 4. Dynamics of the currant bud mite coming out from the blackcurrant bud variety Iliya Muromets in the experimental and control groups 


\section{References}

(1) Babenko, Z. S.; Plekhanov, G. F. Insect phytophages of fruit and berry plants of the Ob forest zone (in Russian); Tomsk University Publishing House: Tomsk, 1982. https://www.openrepository.ru/article?id=830082 (accessed Feb 22, 2020).

(2) Samorodova-Bianchi, G. B.; Volodina, E. V.; Baskakova, L. E. The Chemical Composition of Blackcurrant Berries of Various Species and Groups (in Russian). Bulletin of the VIR 1979, 61, 61-63.

(3) Bayanova, L. V. Evaluation of the Blackcurrant Initial Forms for Resistance to Bud Mite (in Russian). In Progressive methods of cultivating and improving the variety of fruit and berry plants; Priokskiy Publishing House: Tula, 1984; pp 60-65.

(4) Sorokopudov, V. N.; Tkachev, A. V. Database of Black Currant-Berries Cultivars Resistante to Cecidophiyes Ribes Westw (in Russian). In International Conference Genetic collections, isogenic and alloplasmic lines; Novosibirsk, Russia; pp 227-229.

(5) Panfilov, A. A. Phenology of the Bud Mite and of Blackcurrant Forms in the Conditions of the Oryol Region (in Russian). In Actual problems of gardening in Russia and ways to solve them; All-Russian Research Institute for Fruit Crop Breeding: Oryol, Russia, 2007. https://vniispk.ru/pages/activities/scienceactivities/conference-2007/publ-2007-47 (accessed Feb 22, 2020).

(6) Ravkin, A. S. Blackcurrant Selection for Immunity and High Resistance to Bud Mite and Terry (in Russian). In Selection and variety study of blackcurrant; NIZISNP: Michurinsk, 1988; pp 63-68.

(7) Vaskin, M. A.; Sternshis, M. V. Lepidocide and Fitoverm against Phytophages of Blackcurrant (in Russian). Siberian Bulletin of Agricultural Science 2006, 3, 48-53.

(8) Antonyuk, S. I.; Loshitskiy, V. P. Protection of Currants from Bud Mites (in Russian). In Protection of agricultural crops from pests and diseases: Scientific works of NUBiP; NUBiP: Kiev, 1986; pp 63-69.

(9) Berezina, N. V. Biological justification for the use of preparations based on natural complex of avermectins in greenhouses (in Russian). PhD Thesis, Moscow Agricultural Academy named after Timiryazev, Moscow, 1984.

(10) Gorbunov, N. N. Phytosanitary Control of Pests and Weeds of Agricultural Crops in Siberia: A Training Manual (in Russian); NSAU: Novosibirsk, 2001.

\section{Information about Authors}

Svetlana Nikolaevna vitrAZ: Ph.D. in Biology, Associate Professor, Head of the Department of Landscape Architecture, Kuzbass State Agricultural Academy; 5 Markovtsev Str., Kemerovo, 650056, Russia; e-mail: svetlana_vityaz@mail.ru.

Evgeniya Alekseevna DYUKOVA: Senior Lecturer, Department of Landscape Architecture, Kuzbass State Agricultural Academy; 5 Markovtsev Str., Kemerovo, 650056, Russia; e-mail: jeniadulova@mail.ru. 